\title{
Erratum to: Temporal Development of HF-Excited Langmuir and Ion Turbulence at Arecibo
}

\author{
F. T. Djuth ${ }^{1}$ D. F. DuBois ${ }^{2}$
}

Published online: 20 October 2015

(C) Springer Science+Business Media Dordrecht 2015

\section{Erratum to: Earth Moon Planets (2015) 116:19-53 \\ DOI 10.1007/s11038-015-9458-x}

Unfortunately, in the original publication of this article, Eq. (1) has been incorrectly published. Correct Eq. (1) is given below:

$$
\omega_{r}^{2}=\omega_{p e}^{2}+\sin ^{2} \theta \omega_{c e}^{2}+\frac{3 k_{ \pm}^{2} \kappa T_{e}}{m_{e}}
$$

The online version of the original article can be found under doi:10.1007/s11038-015-9458-x.

F. T. Djuth

fdjuth@geospace-research.com

1 Geospace Research, Inc., 525 South Douglas Street, El Segundo, CA 90245, USA

2 Lodestar Research, Corp., 2400 Central Avenue, Boulder, CO 80301, USA 